The final, definitive version of this paper has been published in Journal of Cellular Plastics, 44/5, September/2008 pp. 415-434 by SAGE Publications Ltd. All rights reserved. (C) SAGE Publications Ltd 2008 http://cel.sagepub.com/cgi/content/abstract/44/5/415

\title{
Degradation of Elastic Modulus of Progressively-Crushable Foams in Uniaxial Compression
}

\author{
E.A. Flores-Johnson ${ }^{1}$, Q.M. Li ${ }^{1 *}$, R.A.W. Mines ${ }^{2}$ \\ ${ }^{1}$ School of Mechanical, Aerospace and Civil Engineering \\ The University of Manchester, Pariser Building, PO Box 88, Manchester M60 1QD, UK \\ ${ }^{2}$ Impact Research Centre, Department of Engineering, University of Liverpool, \\ Liverpool, L69 3GH, U.K.
}

\begin{abstract}
The degradation of apparent modulus in progressively-crushable foams in uniaxial compression is studied in the present paper based on an analysis of the measurement of engineering strain. It shows that the deformation mechanism of the progressive collapse of the foam causes the non-uniform deformation in the foam during uniaxial compression, which leads to the decrease of apparent elastic modulus with the increase of strain in the plateau stress regime. Theoretical predictions are compared with experimental results for different closed-cell polymeric foams with satisfactory agreement. It is also shown that this method is not applicable to the in-plane compression of honeycombs and the numerical modelling based on macroscopic constitutive equation is incapable of predicting the degradation of apparent modulus in progressively-crushable foams.
\end{abstract}

Keywords: strain measurement, crushable foam, degradation of apparent elastic modulus.

* Corresponding author, Email: qingming.li@manchester.ac.uk 


\section{NOTATION}

$\begin{array}{ll}\varepsilon \text { Strain } & \varepsilon_{\mathrm{L}}^{\mathrm{p}} \text { Plastic lock-up strain } \\ \varepsilon^{\mathrm{e}} \text { Elastic strain } & \varepsilon_{\mathrm{y}} \text { Compressive yield strain } \\ \varepsilon^{\mathrm{p}} \text { Plastic strain } & \mathrm{E}_{0} \text { Young's modulus } \\ \varepsilon_{\mathrm{L}} \text { Lock-up strain } & \text { E Apparent elastic modulus } \\ \varepsilon_{\mathrm{L}}^{\mathrm{e}} \text { Elastic lock-up strain } & \sigma_{\mathrm{y}} \text { Compressive yield stress } \\ & \\ \text { Note: all strain definitions are based on engineering strain definition. }\end{array}$

\section{Introduction}

When compressive deformation of crushable rigid foam is progressive, the deformation within the gauge length is non-uniform [1, 2] and the compressive strain based on the conventional engineering strain definition is actually an average strain of the localised deformation over the entire gauge length. Since a phenomenological foam material model is based on the valid definition and measurement of strain components and the uniaxial compression is used as the most important material test to determine several key material parameters, e.g., modulus, plateau stress and lock-up (or densification) strain [3], it is necessary to understand the measurement of the compressive strain and its possible influence on the measurements of other material parameters.

A cellular solid is a collection of regular or irregular thin-walled cells, and its macroscopic compressive behaviour is determined by the compressive behaviour of individual cells and the collective interactions between neighbouring cells. When the single cell is treated as a thin-wall structural element, it may be represented by two different types, i.e. Type-I and Type-II structures [4]. Type-I structures have a stable load-deflection plateau and frequently show hardening feature in the plateau regime. The deformation of a Type-II structure is unstable, which shows softening feature in the load-deflection curve. At large deformations, the plateau regime ends when the interactions between cell wall start to play an important role.

For cellular solids, two types of individual cell behaviour shown in Figure 1(a) and 1(b) lead to two types of macroscopic behaviour in Fig 1(a) and 1(c) respectively [3]. When the cells of a cellular material are characterised by softening, i.e. Type-II structure [4], or perfectly plastic 
behaviours, the macroscopic compressive deformation of the cellular solid is progressive and a perfectly plastic plateau regime is normally observed, which is discussed briefly below.

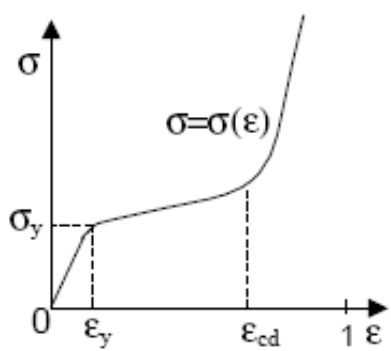

(a)



(b)

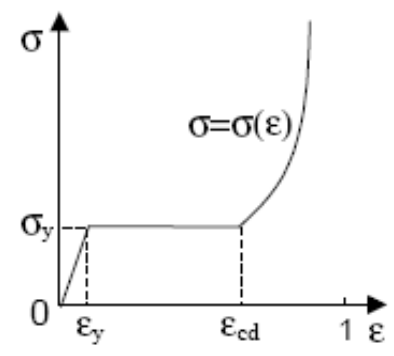

(c)

Fig. 1 Different plateau regimens in Uniaxial compression of a cellular material, (a) stress-strain curve specimen with strain-hardening characteristic; (b) stress-strain for a specimen with strain-softening characteristic; (c) stress-strain curve for a specimen with perfectly-plastic characteristic.

As soon as the compressive stress or strain reaches a critical value, i.e. the compressive failure stress $\sigma_{\mathrm{y}}$ or its corresponding strain $\varepsilon_{\mathrm{y}}$, the cell walls start to collapse. Cell-wall collapse could be one of the cell-wall buckling, the cell-wall breaking and the formation of plastic hinges in the cell wall, or their combinations [5]. The general feature of this process is that the capability of the cell wall to sustain the compressive force after the cell-wall collapse is smaller than its critical value at which the collapse is initiated. The deformation due to the cell-wall collapse is localised within the newly collapsed layer of cells until the collapsed cell start to interact with the neighbouring layer when the local lock-up strain is reached. Further deformation of the collapsed layer of cells requires increased compressive force, which will trigger another neighbouring layer of cells to collapse, and the same process will repeat until all cells are locked-up. This is clearly distinguished from a strain hardening foam that deforms uniformly under compression [6].

After all the cells are locked up (i.e. the total strain reaches the lock-up strain $\varepsilon_{\mathrm{L}}$ which corresponds to the beginning of the densification regime), all the foam cells start to interact with 
each other and the compressive stress increases with further increase of the compressive strain [7]. The deformation across the specimen gauge length becomes uniform.

The existence of an elastic regime is a common feature for most cellular solids. The linear elastic relationship between macroscopic stress and strain is mainly due to the collective microscopic elastic bending of the cell wall. The compressed gas inside the closed cells and the viscoelasticity of the cell walls may be responsible for some non-linear responses of the foam material, e.g. non-linear elasticity and viscoelastic recovery of the foam material $[8,9]$. In practice, the non-linear elastic deformation of the closed cell foam is idealised by a linear elastic relationship in order to simplify the problem. In elastic regime, the compressive stress increases with cell-wall bending deformations and the macroscopic deformation is uniform within the gauge length of the specimen [5].

Experimental evidences have shown that the apparent elastic modulus decreases with increasing total strain in a compressive test when a crushable foam deforms progressively [10]. Similar phenomenon has been observed during uniaxial compression in concrete [11] and FRP-confined concrete [12] and triaxial compression in concrete [13]. The degradation of the elastic modulus is related to material weakening in damage mechanics [14] and attributed to the continuous growth of cracks and porosity [13]. The importance of the study of degradation of the elastic modulus of a concrete structure has been mentioned by Breitenbücher et al. [15] since the change of relevant mechanical properties of the structural material during its service lifetime can be used as an estimator of the level of damage. A search of the available literature indicates a lack of information about the degradation of the elastic modulus in polymeric foams.

This paper presents a method to study the degradation of apparent elastic modulus in uniaxial compression of progressively-crushable foams. Based on a study of strain definition in progressively-crushed foam in uniaxial compression, the degradation of the elastic modulus is formulated in Section 2. A range of experiments are conducted in Section 3 on several types of polymeric forms that deform progressively, from which the experimental results for the degradation 
of elastic modulus with strain are obtained. A FE modelling using ABAQUS is presented in Section 4 to exam the capability of the macroscopic crushable foam model to simulate the progressive collapse of the foam under uniaxial compression and the degradation of the elastic modulus with strain observed in experiments. This study is concluded in Section 5.

\section{Apparent elastic modulus in progressively-crushable foam}

During progressive crushing of a foam specimen under uniaxial compression, two distinct zones exist before the global lock-up strain is reached. One is the crushed zone, in which, compression strain equals lock-up strain and is distributed uniformly in the crushed zone (Figure 2). The other is the elastic zone, which is at the critical state to start crushing. Strain definitions in these zones of progressively crushed foam have been discussed by [2], where an expression for the initial elastic $\varepsilon^{\mathrm{e}}(0)$ and plastic strain $\varepsilon^{\mathrm{P}}(0)$, which are the instantaneous elastic and plastic component of the global compression strain $\varepsilon$ are given by

$$
\begin{aligned}
& \varepsilon^{\mathrm{e}}(0)=\frac{\varepsilon\left(\varepsilon_{\mathrm{L}}^{\mathrm{e}}(0)-\varepsilon_{\mathrm{y}}\right)+\varepsilon_{\mathrm{L}}^{\mathrm{p}}(0) \varepsilon_{\mathrm{y}}}{\varepsilon_{\mathrm{L}}-\varepsilon_{\mathrm{y}}} \\
& \varepsilon^{p}(0)=\frac{\varepsilon_{L}^{p}(0)\left(\varepsilon-\varepsilon_{y}\right)}{\varepsilon_{L}-\varepsilon_{y}}
\end{aligned}
$$

where $\varepsilon$ is the global compression strain, $\varepsilon_{\mathrm{y}}$ is the compression failure strain or compressive yield strain, $\varepsilon_{\mathrm{L}}$ is the total lock-up strain. $\varepsilon_{L}^{e}(0)$ and $\varepsilon_{L}^{p}(0)$ are the initial elastic and plastic lock-up strains, respectively.

The following strain analysis is proposed here to describe the degradation of the apparent elastic modulus in progressively crushed foam.

Since the lock-up strain can be expressed as the sum of its elastic and plastic components [2], i.e., $\varepsilon_{\mathrm{L}}=\varepsilon_{L}^{e}(0)+\varepsilon_{L}^{p}(0)$, Eq.(1a) can be expressed as

$$
\varepsilon^{\mathrm{e}}(0)=\frac{\varepsilon\left(\varepsilon_{\mathrm{L}}-\varepsilon_{\mathrm{L}}^{\mathrm{p}}(0)-\varepsilon_{\mathrm{y}}\right)+\varepsilon_{\mathrm{L}}^{\mathrm{p}}(0) \varepsilon_{\mathrm{y}}}{\varepsilon_{\mathrm{L}}-\varepsilon_{\mathrm{y}}}
$$



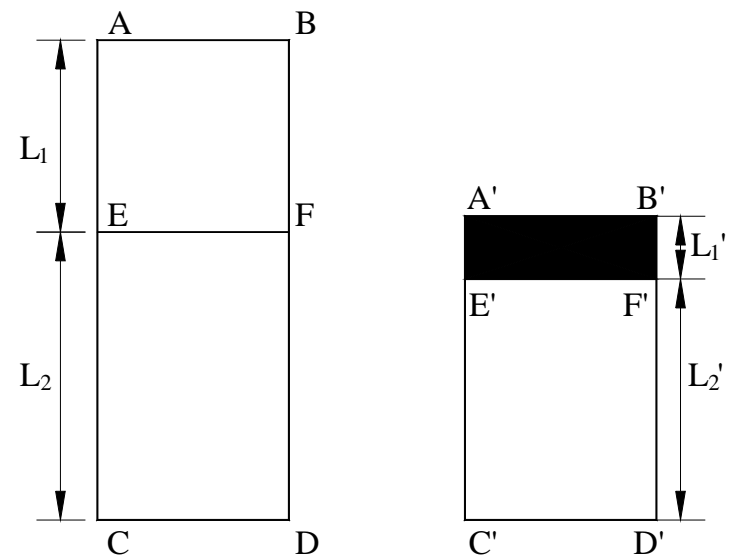

Fig. 2 (a) Original foam specimen, (b) Crushed foam specimen showing crushed region, $\mathrm{L}_{1}$ ’

The apparent elastic modulus at strain $\varepsilon$ can be expressed by

$$
E(\varepsilon)=\frac{\sigma_{y}(\varepsilon)}{\varepsilon^{e}(\varepsilon)}
$$

where the plateau stress, $\sigma_{y}$, is almost a constant, and $\varepsilon^{\mathrm{e}}(\varepsilon)$ is the instantaneous global elastic strain at strain $\varepsilon$ when the viscoelastic recovery is neglected due to the immediate reloading after unloading. The elastic modulus at $\varepsilon=\varepsilon_{\mathrm{y}}$ can be expressed as

$$
\mathrm{E}_{0}=\frac{\sigma_{\mathrm{y}}}{\varepsilon_{\mathrm{y}}}
$$

In the present case, modulus degradation (or variation) $\mathrm{E} / \mathrm{E}_{0}$ can be predicted by considering the variations of global elastic strain determined by Eq.(2) during a uniaxial compression test. Equations (2-4) lead to

$$
\frac{E}{E_{0}}=\frac{\varepsilon_{y}\left(\varepsilon_{L}-\varepsilon_{y}\right)}{\varepsilon\left(\varepsilon_{L}-\varepsilon_{y}-\varepsilon_{L}^{p}(0)\right)+\varepsilon_{y} \varepsilon_{L}^{p}(0)}
$$

It is shown in Eq.(5) that the apparent elastic modulus decreases with the increase of the global compression strain $\varepsilon$. The validity of the above analysis and Eq.(5) will be examined experimentally in the next section. 


\section{Experimental investigation}

\subsection{Materials}

The polymeric foams used in this research are Rohacell 51WF and 110WF which are closed cell rigid PMI (polymethacrylimide) foams with densities of 52 and $110 \mathrm{~kg} / \mathrm{m}^{3}$, respectively, and Divinycell H100 and H130, which are PVC closed-cell foams with densities of 100 and $130 \mathrm{~kg} / \mathrm{m}^{3}$, respectively. The mechanical properties of Rohacell 51WF and Rohacell 110WF foams have been studied by Li et al. [2, 3, 16] and Kuwabara et al. [17]. GDoutos [18, 19], Koissin and Shipsha [20] and Mines and Alias [21] have reported the mechanical properties for Divinycell H100 and H130 foams. Aluminum alloy 5052 over-expanded honeycomb was also tested in the experiments. It has density of $16 \mathrm{~kg} / \mathrm{m}^{3}$, cell size of $7.23 \mathrm{~mm}$, cell side length of $4.56 \mathrm{~mm}$ and cell wall thickness of $0.098 \mathrm{~mm}$, respectively. Aluminum honeycombs have been extensively studied by Gibson and Ashby [5] and Papka and Kyriakides [22, 23].

\subsection{Uniaxial compression test}

Uniaxial compression tests were carried out to determine the strain-stress behaviours of Rohacell and Divinycell polymeric foams and aluminum honeycomb.

The specimens are cubes with 100 mm edges for Rohacell 51WF and 110WF foams, cubes with 25 mm edges for Divinycell H100 and H130 and cubes with $80 \mathrm{~mm}$ edges for aluminum honeycomb. All specimens were tested on a standard $300 \mathrm{kN}$ INSTRON testing machine. The compressive load was applied in quasi-static conditions, at an engineering strain rate of $8.3 \times 10^{-4}$ $\mathrm{s}^{-1}$. Aluminium honeycombs were tested in directions $\mathrm{L}$ and $\mathrm{W}$ as shown in Figure 3. 


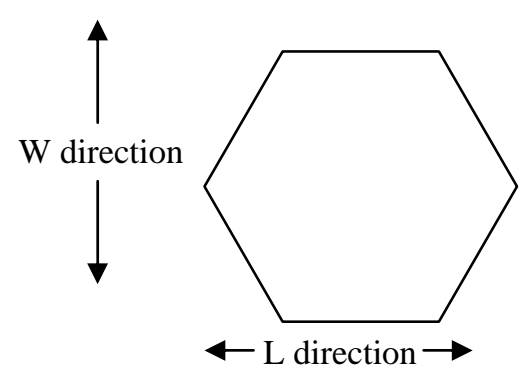

Fig. 3 In-plane L and W directions for honeycombs.

Figure 4 and 5 show the typical compressive stress-strain curves for Rohacell and Divinycell foams, respectively. These curves show an initial elastic behaviour, followed by a plateau regimen in which the stress is almost constant, and then a densification regimen where the stress increases rapidly with the further increase of the strain. Progressive crushing was observed in both Rohacell (Figure 6) and Divinycell foams (Figure 7) in the plateau regime. The compressive stress-strain curves for aluminium honeycomb are shown in Figure 8. Similar to polymeric foams (Rohacell and Divinycell), three regimes are observed in aluminium honeycomb, i.e., the elastic linear regime, the plateau regime, in which hardening is observed in both directions, and the densification regime with an abrupt increase of the stress. L-direction presents higher hardening than W-direction. This occurs because the foam deforms more uniformly in L-direction (Figure 9 and 10). In W-direction, a diagonally localized region of crushing cells are developed and identified without having a progressive crush as in polymeric foams. However, the deformation patterns in both L- and Wdirections in honeycomb specimens are very different from the identified deformation patterns in polymeric foams (Figure 6 and 7), and thus, it is expected that the modulus degradation formula Eq.(5) is not applicable for honeycomb. 




Fig. 4 Typical uniaxial compression stress-strain curves for Rohacell 51WF and 110WF.

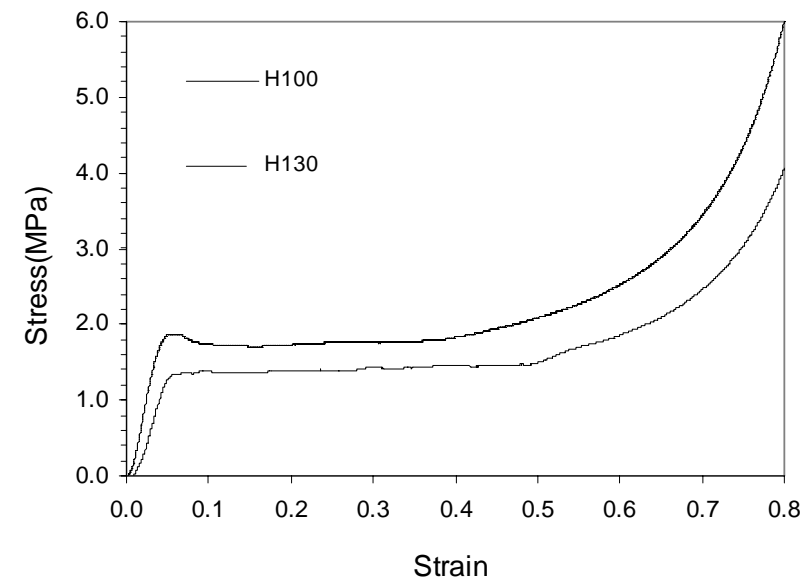

Fig. 5 Typical uniaxial compression stress-strain curves for Divinycell H100 and H130.


Fig. 6 Progressively crushable foam (Rohacell 51 WF), (a) Before uniaxial foam compression test, (b) at 0.45 compression strain and (c) at 0.75 compression strain. 

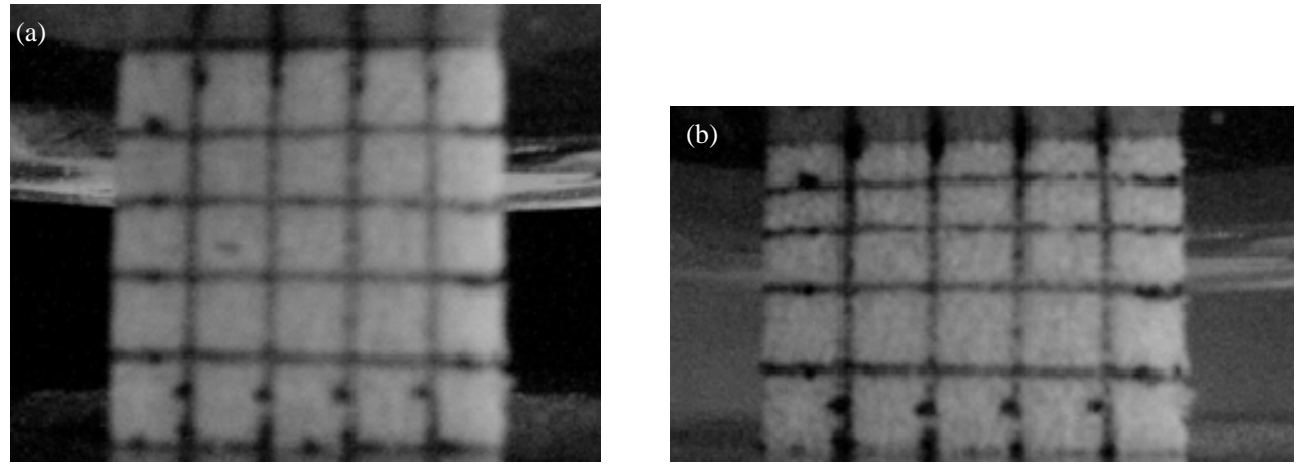

Fig. 7 Deformation of Divinycell H100 foam, (a) Before uniaxial foam compression test, (b) at 0.3 compression strain.

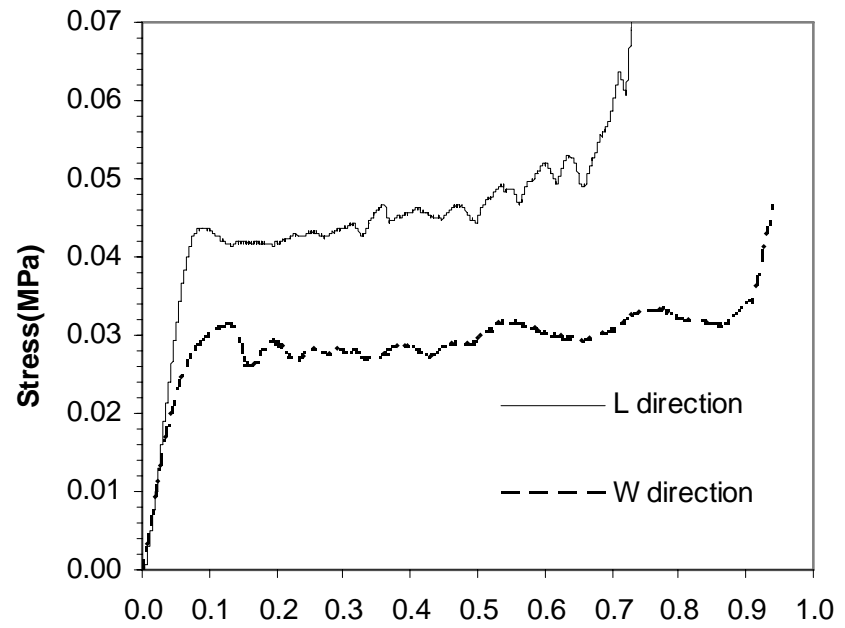

Strain

Fig. 8 Typical uniaxial compression stress-strain curves for aluminium honeycomb in L and W directions.


Fig. 9 Deformation of aluminium honeycombs in L direction, (a) Before uniaxial foam compression test, (b) at 0.3 compression strain, (c) at 0.6 compression strain. 


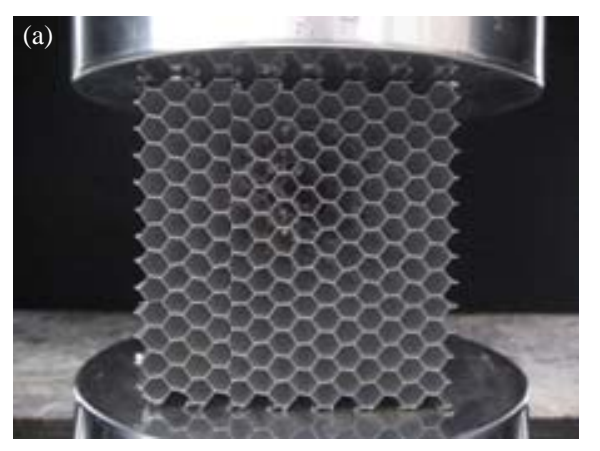

$0 \%$

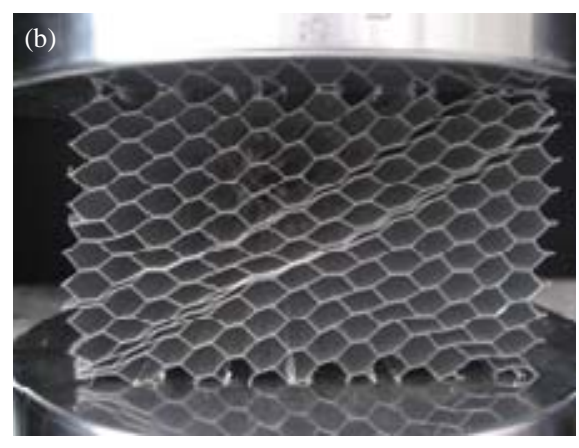

$30 \%$



$60 \%$

Fig. 10 Deformation of aluminium honeycombs in W direction, (a) Before uniaxial foam compression test, (b) at 0.3 compression strain, (c) at 0.6 compression strain.

\subsection{Uniaxial compressive loading-unloading-reloading test}

A series of quasi-static uniaxial compression tests with unloading-reloading cycles at $15 \%$, $30 \%, 45 \%, 60 \%$ and $75 \%$ engineering strains were conducted to measure the apparent elastic modulus. The tests were carried out on a standard $50 \mathrm{kN}$ INSTRON testing machine with same testing conditions and specimen dimensions as those used in uniaxial compression tests. Three specimens were tested for each material. Figure 11 shows the uniaxial compression loading and reloading test curves for Rohacell 51 WF and 110 WF foams, Figure 12 for Divinycell H100 and H130 and Figure 13 for aluminium honeycomb. It can be seen in Figure 11 and 12 that stress-strain curves of Rohacell and Divinycell foams exhibit hysteresis during the unloading-reloading cycles. This hysteresis represents the amount of energy dissipation due to the crushing of the foam. Because of the hysteretic loop, the reloading curve does not overlap the unloading curve, which introduces uncertainty for the determination of the apparent elastic modulus. In following discussion, we adopt a method used in [24] to take the average value of the slope of the unloading and reloading path for the calculation of the apparent elastic modulus E, i.e.

$$
E(\varepsilon)=\frac{E^{U}(\varepsilon)+E^{R}(\varepsilon)}{2}
$$


where $\mathrm{E}^{\mathrm{U}}$ and $\mathrm{E}^{\mathrm{R}}$ are the elastic modulus in the unloading and reloading path, respectively. $\mathrm{E}^{\mathrm{U}}$ and $\mathrm{E}^{\mathrm{R}}$ are determined by the mean slopes of the stress-strain curves between $30 \%$ and $70 \%$ of the plateau stress level [25]. Table 1 shows the average values of the measured apparent elastic modulus $\mathrm{E}$ and the variation of the apparent elastic modulus $\mathrm{E} / \mathrm{E}_{0}$ at different levels of strain $\varepsilon$ for all the materials. The first value of $\varepsilon$ and $\mathrm{E}$ for each material in Table 1 corresponds to the average value of the yield stress $\varepsilon_{\mathrm{y}}$ and elastic modulus $\mathrm{E}_{0}$, respectively. $\mathrm{E}_{0}$ is the Young's modulus measured in the elastic region. Data from Table 1 are depicted in Figure 14 to compare the variation of the apparent elastic modulus $\mathrm{E} / \mathrm{E}_{0}$. It can be seen that polymeric foams of Rohacell and Divinycell show degradation in the apparent elastic modulus in the plateau regime. Both Rohacell and Divinycell show an increase in the apparent elastic modulus in the densification part as a consequence of the increase of the density after all cells have locked-up. Aluminium honeycomb shows an increase in the apparent elastic modulus in L-direction while in W-direction, an initial increase in the apparent elastic modulus followed by a decrease. It is concluded that the compression test of honeycomb specimens in both $\mathrm{L}$ - and $\mathrm{W}$ - directions cannot be treated as material test, and thus, will not be further analysed. However, the progressive crush of the honeycomb in the out-plane direction may have the same nature of the progressive crush of the foam [26, 27], which showed the degradation of the elastic modulus in the uniaxial compression of honeycomb in out-plane direction.



(a)



(b)

Fig. 11 Uniaxial compression loading-unloading-reloading stress-strain curves for (a) Rohacell 51 WF and (b) Rohacell $110 \mathrm{WF}$. 

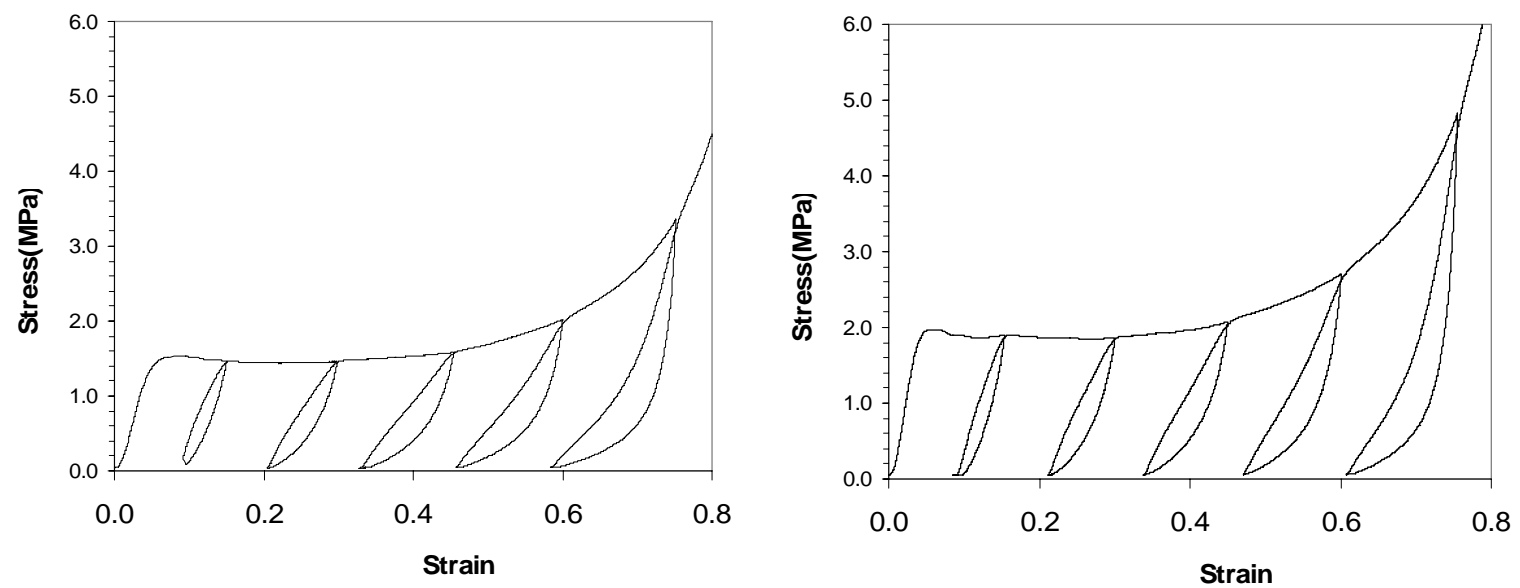

Fig. 12 Uniaxial compression loading-unloading-reloading stress-strain curves for (a) Divinycell H100 and (b) Divinycell H130.

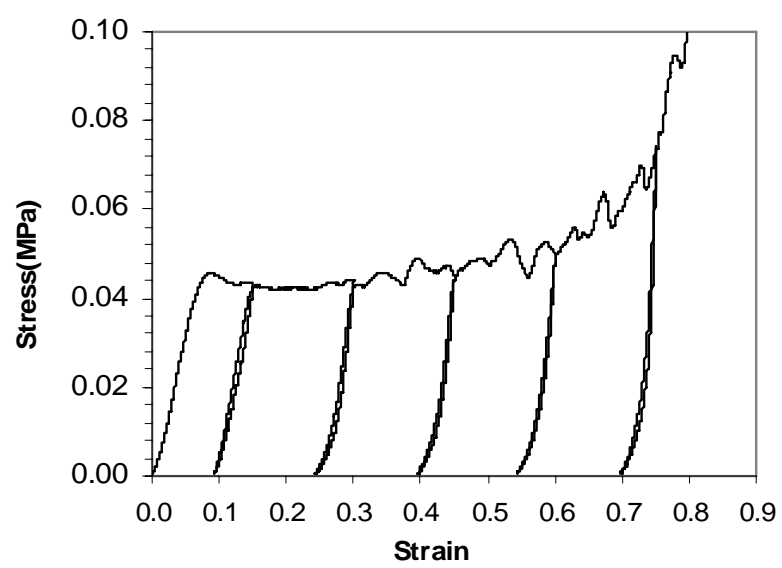

(a)

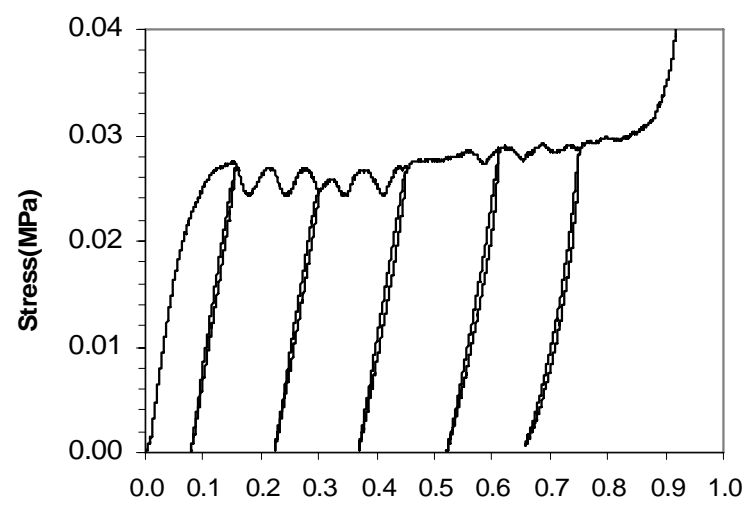

Strain

Fig. 13 Uniaxial compression loading-unloading-reloading stress-strain curves for aluminium honeycomb (a) L direction and (b) W direction.

To verify Eq.(5), parameters $\varepsilon_{\mathrm{y}}, \varepsilon_{\mathrm{L}}$ and $\varepsilon_{L}{ }^{p}(0)$ are needed. The elastic limit $\varepsilon_{\mathrm{y}}$ and the lock-up strain $\varepsilon_{\mathrm{L}}$ were measured from uniaxial compression curves, which are shown in Table 2. The initial plastic lock-up strain $\varepsilon_{L}^{p}(0)$ for Rohacell 51 WF is $61.10 \%$ obtained by Li and Mines [2]. Following the same methodology as in [2], values of ${\varepsilon_{L}}^{p}(0)$ for Rohacell $110 \mathrm{WF}$, Divinycell H100 and H130 were obtained. For this purpose, a series of uniaxial compression tests were carried out at different global strain $\varepsilon$ to obtain the initial plastic strains $\varepsilon^{p}(0)$ by measuring the specimen length immediately after unloading. $\varepsilon_{L}{ }^{p}(0)$ is then obtained using Eq.(1b) which is shown in Table 
3. The average values of $\varepsilon_{L}{ }^{p}(0)$ for Rohacell $110 \mathrm{WF}$, Divinycell H100 and Divinycell H130 are

$58.1 \%, 36.9 \%$ and $34.5 \%$, respectively.

Table 1 Measured apparent elastic modulus and variation of the apparent elastic modulus corresponding to various total strains of Rohacell and Divinycell foams and aluminium honeycombs.

\begin{tabular}{|c|c|c|c|}
\hline FOAM & $\varepsilon(\%)$ & Average E (MPa) & $\mathrm{E} / \mathrm{E}_{0}$ \\
\hline \multirow{6}{*}{$51 \mathrm{WF}$} & 3.82 & 44.58 & 1.00 \\
\hline & 15.00 & 39.35 & 0.88 \\
\hline & 30.00 & 31.83 & 0.71 \\
\hline & 45.00 & 25.77 & 0.58 \\
\hline & 60.00 & 21.87 & 0.49 \\
\hline & 75.00 & 27.24 & 0.61 \\
\hline \multirow{6}{*}{$110 \mathrm{WF}$} & 3.63 & 143.25 & 1.00 \\
\hline & 15.00 & 121.48 & 0.85 \\
\hline & 30.00 & 99.13 & 0.69 \\
\hline & 45.00 & 85.97 & 0.60 \\
\hline & 60.00 & 78.41 & 0.55 \\
\hline & 75.00 & 108.27 & 0.76 \\
\hline \multirow{6}{*}{ H100 } & 5.00 & 35.70 & 1.00 \\
\hline & 15.00 & 23.92 & 0.67 \\
\hline & 30.00 & 15.24 & 0.43 \\
\hline & 45.00 & 12.61 & 0.35 \\
\hline & 60.00 & 13.28 & 0.37 \\
\hline & 75.00 & 21.85 & 0.61 \\
\hline \multirow{6}{*}{ H130 } & 4.90 & 55.48 & 1.00 \\
\hline & 15.00 & 32.22 & 0.58 \\
\hline & 30.00 & 20.00 & 0.36 \\
\hline & 45.00 & 18.42 & 0.33 \\
\hline & 60.00 & 21.90 & 0.39 \\
\hline & 75.00 & 33.47 & 0.60 \\
\hline \multirow{6}{*}{$\begin{array}{l}\text { Aluminium } \\
\text { honeycomb } \\
\text { L direction }\end{array}$} & 3.63 & 0.73 & 1.00 \\
\hline & 15.00 & 0.81 & 1.11 \\
\hline & 30.00 & 0.98 & 1.36 \\
\hline & 45.00 & 1.27 & 1.75 \\
\hline & 60.00 & 1.35 & 1.86 \\
\hline & 75.00 & 2.01 & 2.77 \\
\hline \multirow{6}{*}{$\begin{array}{l}\text { Aluminium } \\
\text { honeycomb } \\
\text { W direction }\end{array}$} & 3.63 & 0.30 & 1.00 \\
\hline & 15.00 & 0.35 & 1.13 \\
\hline & 30.00 & 0.33 & 1.10 \\
\hline & 45.00 & 0.32 & 1.06 \\
\hline & 60.00 & 0.29 & 0.96 \\
\hline & 75.00 & 0.32 & 1.08 \\
\hline
\end{tabular}




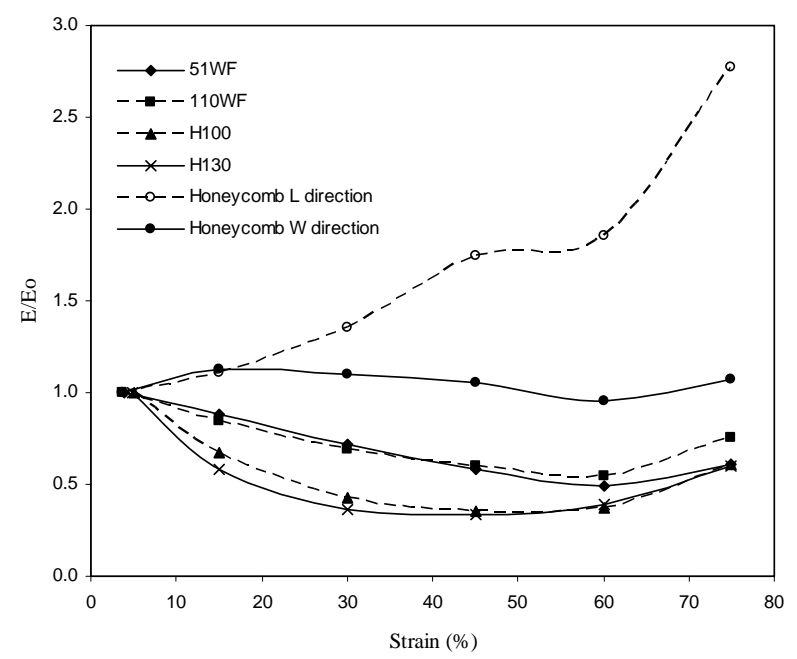

Fig. 14 Variation of apparent elastic modulus $E / E_{0}$ vs global compression engineering strain for different materials.

Figure 15(a) and 15(b) show the predictions from Eq.(5) and the experimental results for the apparent elastic modulus (Table 1) for Rohacell 51 WF, Rohacell 110 WF, Divinycell H100 and Divinycell H130 foams, respectively. Both predictions and experimental results clearly demonstrate the reduction of the elastic modulus with the increase of strain in the plateau regime. For Rohacell $110 \mathrm{WF}$ foam, at $60 \%$ of total strain, the reduction is approximately $45 \%$ from the initial value which is quite significant. For Divinycell H130 foam, an even higher reduction (up to 67\%) of the initial elastic modulus at $45 \%$ of total strain is found. Good quantitative agreement between predictions from Eq.(5) and experimental results in the plateau regime shows that the proposed model can explain the observed degradation of the elastic modulus with the increase of strain. Therefore, the observed degradation of the apparent elastic modulus is determined by the nonuniformity of the deformation in the specimen, rather than the material damage.

Table 2 Measured failure and lock-up strain of Rohacell and Divinycell foams.

\begin{tabular}{ccc}
\hline FOAM & Average $\varepsilon_{y}(\%)$ & Average $\varepsilon_{\mathrm{L}}(\%)$ \\
\hline $51 \mathrm{WF}$ & 3.9 & 68.7 \\
\hline $110 \mathrm{WF}$ & 3.6 & 65.3 \\
\hline H100 & 5.8 & 50.2 \\
\hline H130 & 5.5 & 49.7 \\
\hline
\end{tabular}




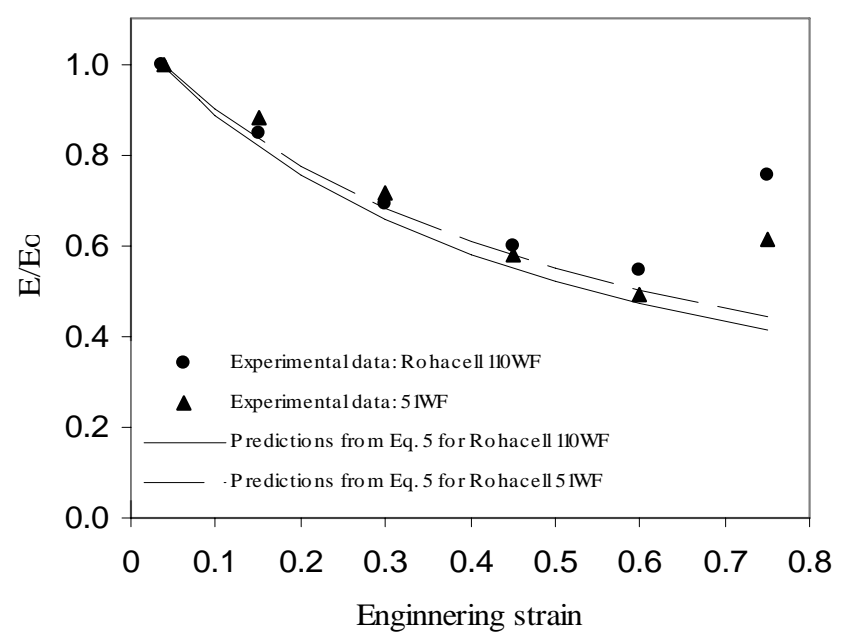

(a)



(b)

Fig. 15 Experimental and predicted results of the variation of apparent elastic modulus E/Eo for (a) Rohacell foams and (b) Divinycell foams.

Table 3 Measured initial plastic strain and calculated initial plastic lock-up strain of Rohacell and Divinycell foams.

\begin{tabular}{cccc}
\hline FOAM & $\varepsilon(\%)$ & Average $\varepsilon^{\mathrm{p}}(0)(\%)$ & $\varepsilon_{\mathrm{L}}{ }^{\mathrm{p}}(0)(\%)$ \\
\hline \multirow{3}{*}{$110 \mathrm{WF}$} & 20 & 15.8 & 59.6 \\
& 35 & 29.7 & 58.4 \\
& 45 & 37.7 & 56.3 \\
\hline \multirow{3}{*}{ H100 } & 20 & 12.1 & 37.5 \\
& 35 & 23.1 & 34.8 \\
& 45 & 33.1 & 38.3 \\
\hline \multirow{3}{*}{ H130 } & 20 & 11.3 & 34.4 \\
& 35 & 23.2 & 34.7 \\
\hline
\end{tabular}

\section{Numerical Simulations}

ABAQUS finite element computer code Version 6.5 was used to model the behavior of Rohacell 51WF foam for uniaxial compressive and uniaxial compressive loading-unloading-reloading tests. CRUSHABLE FOAM model was used with following parameters: Young's Modulus E = $22 \mathrm{MPa}$, Poisson's ratio $v=0$, compressive yield stress $\sigma_{\mathrm{y}}=0.85 \mathrm{MPa}$, and Hydrostatic yield stress $\mathrm{P}=0.82$ MPa. In order to get mentioned parameters and CRUSHABLE FOAM HARDENING tabular data, 
experimental results from uniaxial compression test were used. Hydrostatic yield stress parameter was taken from previous research on Rohacell 51WF foam in [16]. NLGEOM option for large deformations was activated.

The geometry of the foam cube used in numerical modeling is $100 \times 100 \mathrm{~mm}$. The model was meshed using C3D8R elements. In total, 1000 elements were used to model the foam cube. The model was compressed by a flat-faced rigid plate, as shown in Fig. 16.

To validate the ABAQUS model, a uniaxial compressive test was simulated. Figure 17 compares experimental results in Figure 4 for Rohacell 51WF. A very good agreement between the ABAQUS simulation and the experimental result for uniaxial compressive test is observed.

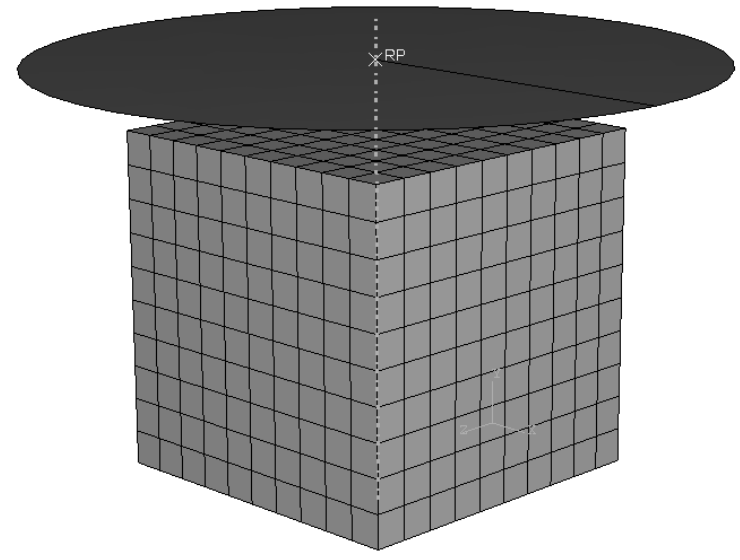

Fig. 16 3D finite element meshing used for modeling the compressive behavior of Rohacell 51WF foam.

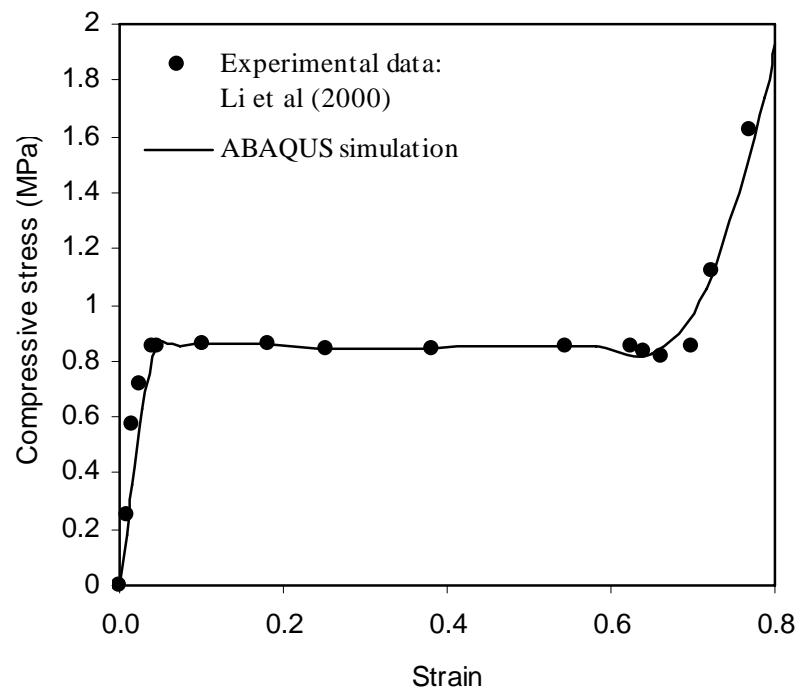

Fig. 17 Comparison of experimental and numerical results stress vs strain results of uniaxial compressive test of Rohacell 51WF foam. 
A quasi-static uniaxial compression tests with unloading-reloading stages at $15 \%, 30 \%, 45 \%$, $60 \%$ and $75 \%$ strains were performed using numerical simulations. Figure 18 shows the strainstress curve obtained during the simulation. The apparent elastic modulus was measured in the same way as the experimental test to monitor its change during the loading-unloading-reloading process in the numerical simulation. Figure 19 shows the variation of the apparent modulus $\mathrm{E} / \mathrm{E}_{0}$ with the global compressive engineering strain. It can be seen that the value of $E / E_{0}$ from numerical simulation increases with strain, which is opposite to the experimental observations. Figure 20 shows the behaviour of the foam corresponding to different strains (0\%, $45 \%$ and $75 \%)$ during uniaxial compressive test. The uniformly-distributed deformation in Figure 20 is contrast to the progressive crushing observed in experiments (Figure 6 and 7). This is attributed to the fact that numerical simulation based on macroscopic foam model is unable to reproduce the progressive crushing mechanism of the foam.

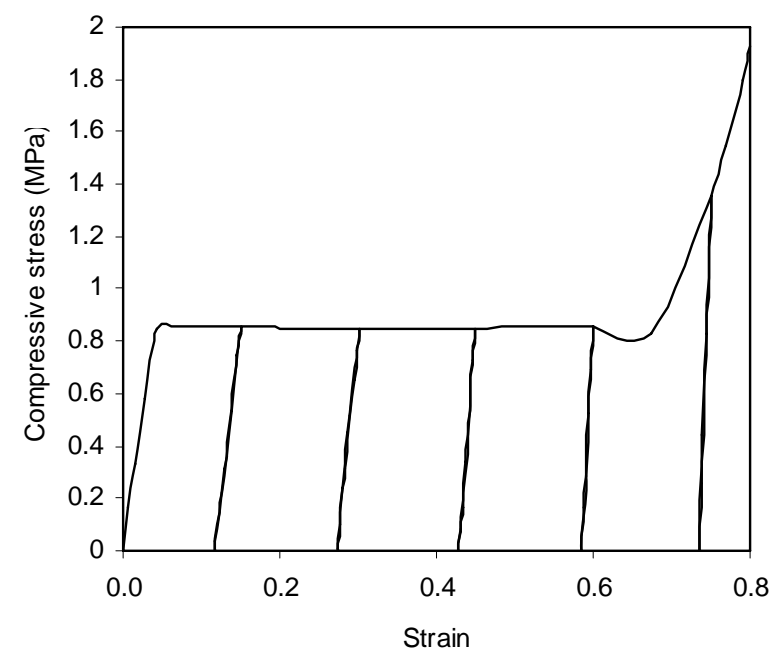

Fig. 18 Numerical simulation results of uniaxial compressive loading-unloading-reloading test of Rohacell 51WF. 


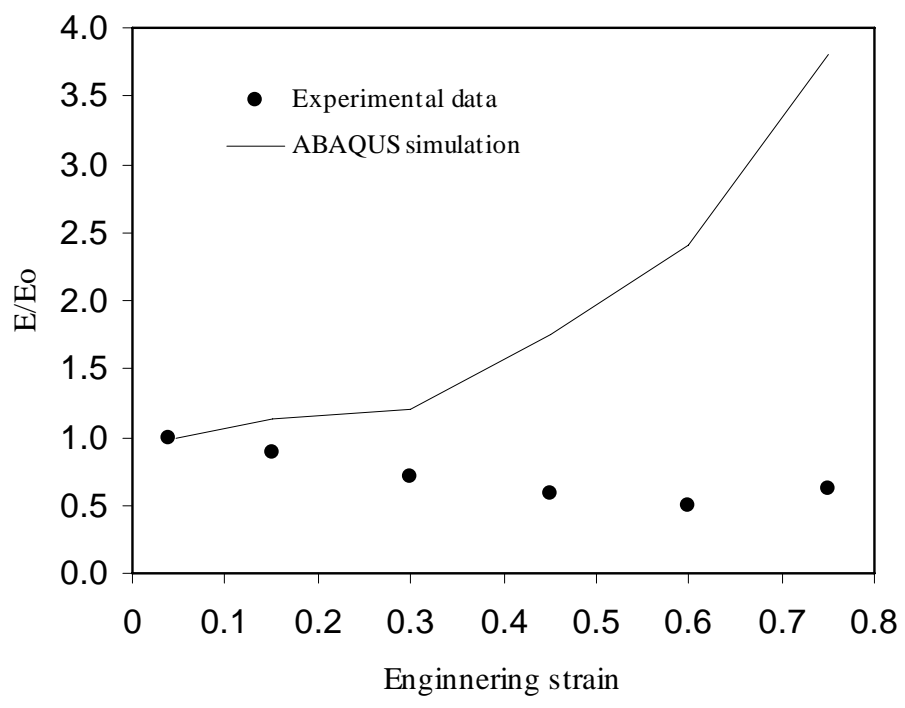

Fig. 19 Variation of the apparent modulus $E_{/} E_{0}$ vs engineering strain.



(a)

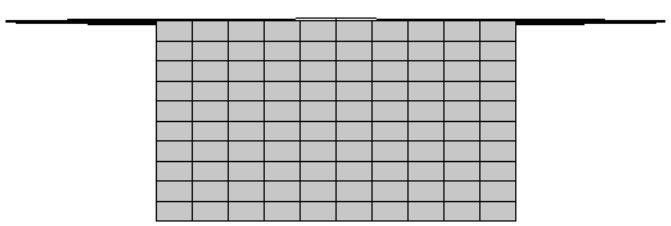

(b)

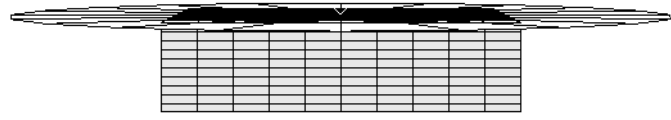

(c)

Fig. 20 Deformation of Rohacell 51 WF foam during numerical simulation test. (a) Before uniaxial compression test, (b) at 0.45 compression strain and (c) at 0.75 compression strain. 


\section{Conclusions}

The degradation of the apparent elastic modulus in progressively crushable foam observed in uniaxial compressive tests is attributed to the progressive nature of the foam rather than the growth of the damage. A formula based on the strain analysis and measurement in uniaxial compression of the progressively crushable foam is derived to determine the degradation of the elastic modulus with the increase of strain. Good agreements between the predicted results and experimental results for several polymeric foams are achieved. The in-plane compression of honeycomb has different deformation mechanism from the cellular foam, and therefore, the degradation of the apparent elastic modulus is not observed in the compressive tests on honeycomb. It is also demonstrated that FE modelling based on macroscopic foam model is incapable of predicting the progressive crush of the foam, and therefore, the degradation of the apparent elastic modulus in a uniaxial compressive test.

Acknowledgments: Rohacell structural foams were supplied by Degussa AG, Röhm GmbH \& Co. The author E.A. Flores-Johnson was supported by CONACYT No. 172677 scholarship from the Mexican Government.

\section{References}

1. Fatima Vaz, M. and Fortes, M.A. (1993). Characterization of deformation bands in the compression of cellular materials, Journal of materials science letters, 12(17): p. 1408-10.

2. Li, Q.M. and Mines, R.A.W. (2002). Strain measures for rigid crushable foam in uniaxial compression, Strain, 38(4): p. 132-40.

3. Li, Q.M., Magkiriadis, I., and Harrigan, J.J. (2006). Compressive strain at the onset of densification of cellular solids, Journal of cellular plastics, 42(5): p. 371-392.

4. Calladine, C.R. and English, R.W. (1984). Strain-rate and inertia effects in the collapse of two types of energy-absorbing structure, International journal of mechanical sciences, 26(11): p. 689701.

5. Gibson, L.J. and Ashby, M.F. (1997). Cellular Solids: Structure and Properties. 2nd ed. Cambridge: Cambridge University Press. 
6. Zhang, J., Kikuchi, N., Li, V., Yee, A., and Nusholtz, G. (1998). Constitutive modeling of polymeric foam material subjected to dynamic crash loading, International journal of impact engineering, 21(5): p. 369-386.

7. Elliott, J.A., A.H., W., Hobdell, J.R., Eeckhaut, G., Oldman, R.J., Ludwig, W., Boller, E., Cloetens, P., and Baruchel, J. (2002). In-situ deformation of an open-cell flexible polyurethane foam characterised by 3D computed microtomography, Journal of materials science, 37(8): p. 1547-55.

8. Rodríguez-Pérez, M.A., Díez-Gutiérrez, S., and De Saja, J.A. (1998). The recovery behavior of crosslinked closed cell polyolefin foams, Polymer Engineering \& Science, 38(5): p. 831-837.

9. Rodríguez-Pérez, M.A., Velasco, J.I., Arencón, D., Almanza, O., and De Saja, J.A. (2000). Mechanical characterization of closed-cell polyolefin foams, Journal of Applied Polymer Science, 75(1): p. 156-166.

10. Li, Q.M. and Mines, R.A.W. (1999). Strain localization in rigid crushable foam during uniaxial compression. Liverpool, University of Liverpool, Impact Research Centre Report No. IRC/183/99.

11. Sinha, B.P., Gerstle, K.H., and Tulin, G.L. (1964). Stress-Strain Relations for Concrete Under Cyclic Loading, Journal of American Concrete Institute, 61(2): p. 195-212.

12. Lam, L., Teng, J.G., Cheung, C.H., and Xiao, Y. (2006). FRP-confined concrete under axial cyclic compression, Cement and Concrete Composites, 28(10): p. 949-958.

13. Imran, I. and Pantazopoulou, S.J. (1996). Experimental Study of Plain Concrete under Triaxial Stress, ACI Materials Journal, 93(6): p. 589-601.

14. Lemaitre, J. and Chaboche, J.L. (1990). Mechanics of solid materials. Cambrige: Cambridge University Press.

15. Breitenbücher, R., Ibuk, H., and Alawieh, H. (2007). Influence of cyclic loading on the degradation of mechanical concrete properties, in Advances in Construction Materials 2007, Springler Berlin Heidelberg, Berlin. p. 317-324.

16. Li, Q.M., Mines, R.A.W., and Birch, R.S. (2000). The crush behaviour of Rohacell-51WF structural foam, International Journal of Solids and Structures, 37(43): p. 6321-6341.

17. Kuwabara, A., Ozasa, M., Shimokawa, T., Watanabe, N., and Nomoto, K. (2005). Basic mechanical properties of balloon-type TEEK-L polyimide-foam and TEEK-L filled aramidhoneycomb core materials for sandwich structures, Advanced composite materials, 14(4): p. 343363.

18. GDoutos, E.E. and Abot, J.L. (2002). Indentation of a PVC Cellular Foam, in Recent Advances in Experimental Mechanics, Kluwer Academics Publishers. p. 55-64.

19. GDoutos, E.E., Daniel, I.M., and Wang, K.-A. (2002). Failure of cellular foams under multiaxial loading, Composites. Part A, Applied science and manufacturing, 33(2): p. 163-176.

20. Koissin, V. and Shipsha, A. (2006). Deformation of Foam Cores in Uniaxial CompressionTension Cycle, Journal of Sandwich Structures and Materials, 8(5): p. 395-406. 
21. Mines, R.A.W. and Alias, A. (2002). Numerical simulation of the progressive collapse of polymer composite sandwich beams under static loading, Composites. Part A, Applied science and manufacturing, 33(1): p. 11-26.

22. Papka, S.D. and Kyriakides, S. (1994). In-plane compressive response and crushing of honeycomb, Journal of the Mechanics and Physics of Solids, 42(10): p. 1499-532.

23. Papka, S.D. and Kyriakides, S. (1998). Experiments and full-scale numerical simulations of inplane crushing of a honeycomb, Acta materialia, 46(8): p. 2765-76.

24. Sugimura, Y., Meyer, J., He, M.Y., Bart-Smith, H., Grenstedt, J., and Evans, A.G. (1997). On the mechanical performance of closed cell Al alloy foams, Acta materialia, 45(12): p. 5245-59.

25. Hanssen, A.G., Hopperstad, O.S., Langseth, M., and Ilstad, H. (2002). Validation of constitutive models applicable to aluminium foams, International journal of mechanical sciences, 44(2): p. 359406.

26. Mohr, D. and Doyoyo, M. (2003). Nucleation and propagation of plastic collapse bands in aluminum honeycomb, Journal of Applied Physics, 94(4): p. 2262-2270.

27. Yang, M. and Qiao, P. (2008). Quasi-static Crushing Behavior of Aluminum Honeycomb Materials, Journal of Sandwich Structures and Materials, 10(2): p. 133-160. 